\title{
Synthesis and characterization of a narrow size distribution of zinc oxide nanoparticles
}

\author{
This article was published in the following Dove Press journal: \\ International Journal of Nanomedicine \\ 4 July 2011 \\ Number of times this article has been viewed
}

\author{
A Khorsand Zak ${ }^{1,2}$ \\ R Razali' \\ WH Abd Majid' \\ Majid Darroudi ${ }^{2}$ \\ 'Low Dimensional Material Research \\ Center, Department of Physics, \\ Faculty of Science, University of \\ Malaya, Kuala Lumpur, Malaysia; \\ ${ }^{2}$ Department of Chemistry, Faculty \\ of Science, Ferdowsi University of \\ Mashhad, Mashhad, Iran
}

\begin{abstract}
Zinc oxide nanoparticles (ZnO-NPs) were synthesized via a solvothermal method in triethanolamine (TEA) media. TEA was utilized as a polymer agent to terminate the growth of $\mathrm{ZnO}$-NPs. The ZnO-NPs were characterized by a number of techniques, including X-ray diffraction analysis, transition electron microscopy, and field emission electron microscopy. The $\mathrm{ZnO}-\mathrm{NPs}$ prepared by the solvothermal process at $150^{\circ} \mathrm{C}$ for 18 hours exhibited a hexagonal (wurtzite) structure, with a crystalline size of $33 \pm 2 \mathrm{~nm}$, and particle size of $48 \pm 7 \mathrm{~nm}$. The results confirm that TEA is a suitable polymer agent to prepare homogenous $\mathrm{ZnO}-\mathrm{NPs}$.
\end{abstract}

Keywords: zinc oxide, solvothermal, nanoparticles, nanopowders

\section{Introduction}

Understanding the mechanisms of the human body at the molecular and nanometer scale has improved tremendously, but developments in therapeutic options for treating severe and debilitating diseases such as cancer and autoimmunity have lagged by comparison. ${ }^{1}$ In this regard, nanomedicine, which is the application of nanotechnology to medical problems, can offer new approaches in therapy. The application of nanotechnology in biology requires further studies for the development of new materials in the nanosize range. These materials have many potential applications in biological science and clinical medicine., ${ }^{2,3}$

One of the better-known materials that have been widely used for medical applications is zinc oxide nanoparticles ( $\mathrm{ZnO}-\mathrm{NPs}$ ). It is not too far from the truth to say that the $\mathrm{ZnO}$ is a magic material because of its wide area of applications and flexibility of preparation in different morphologies with different properties. Reflecting the basic properties of $\mathrm{ZnO}$, fine particles of the oxide have deodorizing and antibacterial action, and for that reason are added into various materials including cotton fabric, rubber, and food packaging. ${ }^{4,5}$ $\mathrm{ZnO}$ is widely used to treat a variety of other skin conditions, in products such as baby powder and barrier creams to treat diaper rashes, and in calamine cream, antidandruff shampoos, and antiseptic ointments. ${ }^{6,7}$ It is also a component in tape (called "zinc oxide tape") used by athletes as a bandage to prevent soft tissue damage during workouts. ${ }^{8}$ Therefore, several new routes have been developed to synthesize $\mathrm{ZnO}-\mathrm{NPs}$, such as a wet polymerization method, sol-gel, sol-gel combustion, precipitation, hydrothermal, solvothermal, chemical vapor deposition (CVD), microwave assisted, a sonochemical method, and thermal oxidation. ${ }^{9-18}$ Some of these methods have limitations. For example, it is not easy to control the growth of the $\mathrm{ZnO}$ nanostructures in the microwave, sol-gel, and sol-gel combustion methods because of the speed of the reactions. We have tried
Correspondence: A Khorsand Zak

Low Dimensional Material Research Center, Department of Physics, Faculty of Science, University of Malaya, 50603,

Kuala Lumpur, Malaysia

Tel +60 I2 2850849

Fax +60 $379674 \mid 46$

Email alikhorsandzak@gmail.com 
to develop a better controlled method that is reliable, safe, and cheap.

In this work, a simple solvothermal method was used to prepare the $\mathrm{ZnO}-\mathrm{NPs}$. The aim of this research is the preparation of $\mathrm{ZnO}-\mathrm{NPs}$ with a narrow size distribution that are suitable for medical applications such as in sunscreen protection. Triethanolamine (TEA) was used as a polymerization agent in order to control the morphology of the $\mathrm{ZnO}-\mathrm{NPs}$ because of its special structure. The reaction mechanism and effect of TEA were investigated.

\section{Experimental}

Zinc acetate $\left(\mathrm{Zn}\left(\mathrm{CH}_{3} \mathrm{COO}\right)_{2} \cdot 2 \mathrm{H}_{2} \mathrm{O}\right)$, ethanol, and TEA were used as starting materials. $0.5 \mathrm{M}$ zinc acetate solution was prepared by dissolving $7.68 \mathrm{~g}$ of zinc acetate in $35 \mathrm{~mL}$ of ethanol. The solution was stirred at $60^{\circ} \mathrm{C}$, and then the TEA was added to the solution, all at one time. The molar ratio of $\mathrm{TEA} / \mathrm{Zn}^{2+}$ was fixed at $1: 1$. The solution was stirred at $60^{\circ} \mathrm{C}$ for 1 hour. After the stirring period, a clear and homogenous solution was obtained. The $\mathrm{Zn}^{2+}$ solution was then aged at room temperature for another hour. The solutions were poured in a stainless steel autoclave in a $50 \mathrm{~mL}$ Teflon vessel, and placed in the furnace for 18 hours at $150^{\circ} \mathrm{C}$. The sample was then cooled down to room temperature. The formed white precipitates were dispersed in ethanol solution (30\% in deionized water). The precipitates were separated by centrifugation of the mixture (4000 rpm for 4 minutes) at room temperature. These washing steps were repeated 3 times to remove the TEA polymers. Subsequently, the white precipitates were dried in an oven at $60^{\circ} \mathrm{C}$ overnight.

The structure of the prepared $\mathrm{ZnO}-\mathrm{NPs}$ was characterized by powder X-ray diffraction (XRD, Philips, X'pert, $\mathrm{Cu} \mathrm{K}_{\alpha}$ ). Field emission scanning electron microscopy (FESEM) and transmission electron microscopy (TEM, Hitachi H-7100 electron microscope) were used to study the morphology of the ZnO-NPs. The UV-vis spectra were recorded over the range of 200-1000 nm by a UV-vis Evolution $300 \mathrm{PC}$ (Thermo Scientific, Japan).

\section{Results and discussion}

\section{The mechanism of ZnO-NPs formation}

In the solvothermal process, alcohol plays a very important role in contributing the unoccupied oxygen to $\mathrm{Zn}^{2+}$ in order to form $\mathrm{ZnO} .{ }^{19}$ The formed $\mathrm{ZnO}$ seeds are attracted to some of the TEA chains because of the ionic-dipolar interaction between the hydrogen atoms in the polymer and oxygen in the $\mathrm{ZnO}$. The $\mathrm{ZnO}-\mathrm{NPs}$ will grow with the association of the $\mathrm{ZnO}$ seeds. On the other hand, some of the TEA chains are attracted to each other by hydrogen-bonding forces. So, the growth of the particles will be eliminated, because the polymer chains do not permit the $\mathrm{ZnO}$ seeds to reach each other easily. The complete process is shown in Figure 1.

\section{Fourier transform infrared spectroscopy (FTIR) analysis}

Figure 2 shows the FTIR of the ZnO-NPs prepared by the solvothermal method, in the range of $4000-280 \mathrm{~cm}^{-1}$. A broad absorption band was observed at around $375 \mathrm{~cm}^{-1}$. The band at $375 \mathrm{~cm}^{-1}$ corresponds to the $\mathrm{E}_{2}$ mode of hexagonal $\mathrm{ZnO}$ (Raman active). ${ }^{11}$ There were several small absorption bands at 930, 1050, and $3400 \mathrm{~cm}^{-1}$. These absorption bands were likely related to $\mathrm{CO}_{2}(\mathrm{C}-\mathrm{O})$ and $\mathrm{H}_{2} \mathrm{O}(\mathrm{O}-\mathrm{H})$ absorbed from the atmosphere (air), and can therefore be neglected. The FTIR results show the high purity of the obtained $\mathrm{ZnO}-\mathrm{NPs}$.

\section{XRD}

The XRD pattern of the ZnO-NPs prepared by the solvothermal process at $150^{\circ} \mathrm{C}$ for 18 hours is shown in Figure 3. All detectable peaks can be indexed to $\mathrm{ZnO}$ wurtzite structure (PDF code no: 00-036-1451). The wurtzite lattice parameters, for example the values of $d$, the distances between adjacent crystal planes $(h k l)$, were calculated from the Bragg equation, $\lambda=2 d \sin \theta$. The lattice constants $a, b$, and $c$; the inter-planar angles, the angle $\varphi$ between the planes $\left(h_{1} k_{1} l_{1}\right)$ of spacing $d_{1}$ and the plane ( $h_{2} k_{2} l_{2}$ ) of spacing $d_{2}$; and $V$, the primary cell volumes, were calculated from the Lattice Geometry equation. ${ }^{20}$ The (100) and (002) planes were used to calculate the lattice parameters of the prepared $\mathrm{ZnO}-\mathrm{NPs}$, and the following values were obtained: $d_{(100)}=0.2787 \mathrm{~nm}, d_{(002)}=0.2598 \mathrm{~nm}, a=b=0.3218 \mathrm{~nm}$, $c=0.5195 \mathrm{~nm}, \varphi=90^{\circ}$, and $V=46.58 \mathrm{~nm}^{3}$.

The Scherrer equation, $D=\left(k \lambda / \beta_{h k l} \cos \theta\right)$, was used to determine the crystalline sizes of the $\mathrm{ZnO}$-NPs where $D$ is the crystalline size in nanometers (nm), $\lambda$ is the wavelength of the radiation ( $1.54056 \AA$ for $\mathrm{CuK}_{\alpha}$ radiation), $k$ is a constant equal to $0.94, \beta_{h k l}$ is the peak width at half-maximum intensity, and $\theta$ is the peak position. The (102) plane was chosen to calculate the crystalline size (either plane can be used for this purpose). The crystalline sizes of the $\mathrm{ZnO}-\mathrm{NPs}$ prepared at $150^{\circ} \mathrm{C}$ for 18 hours were observed to be $33 \pm 2 \mathrm{~nm}$.

\section{Optical properties}

The room temperature UV-vis absorption spectra of ZnO-NPs are shown in Figure 4. The ZnO-NPs were dispersed in ethanol with concentration of $0.1 \% \mathrm{wt}$ and then the solution was used to perform the UV-vis measurement. The spectrum reveals a characteristic absorption peak of $\mathrm{ZnO}$ at wavelength 

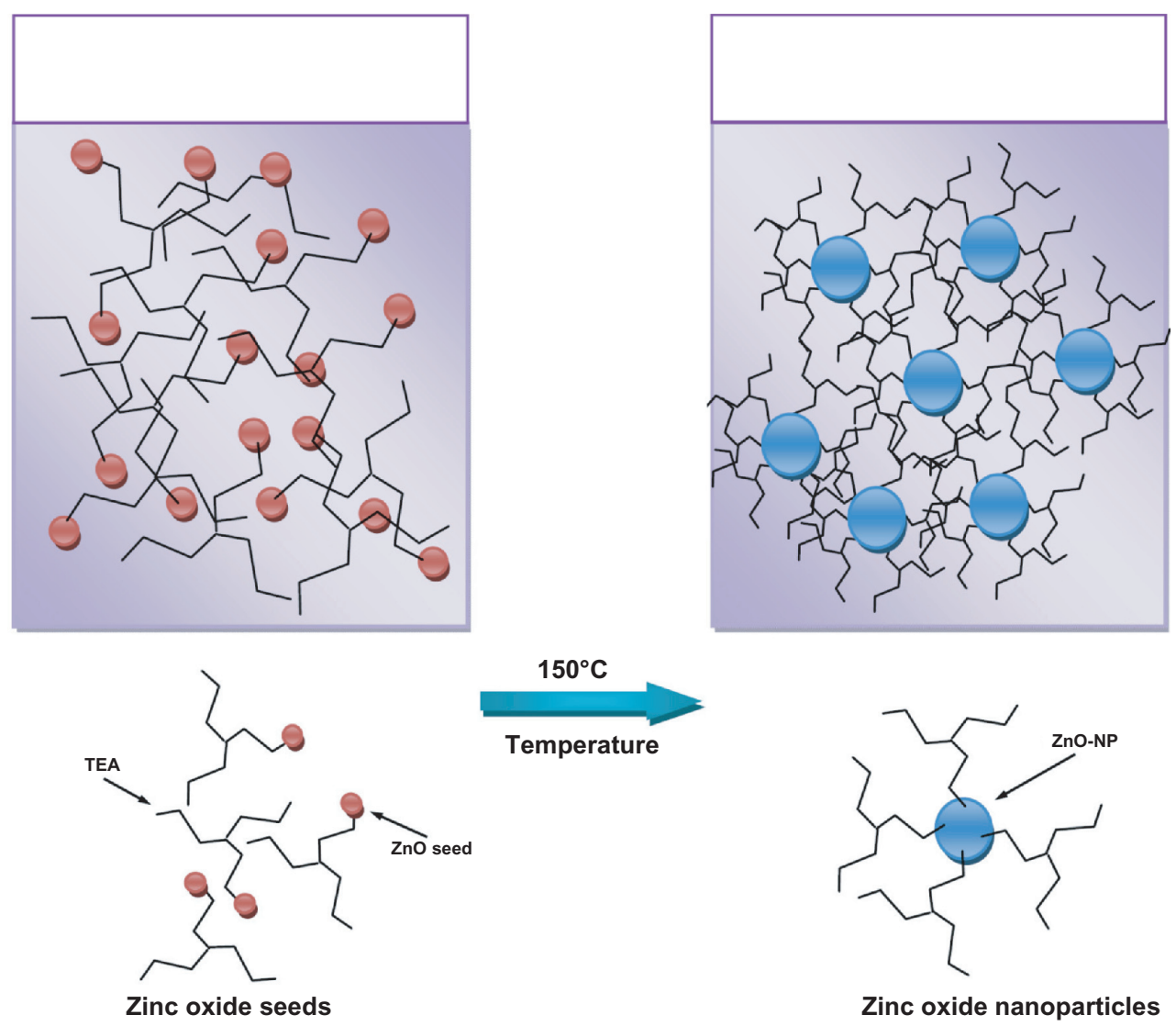

$150^{\circ} \mathrm{C}$
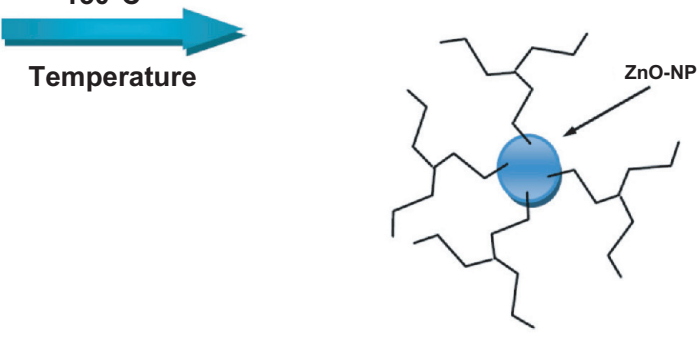

Zinc oxide nanoparticles

Figure I The schematic image of formation of the zinc oxide nanoparticles from the zinc oxide seed, and the role of triethanolamine as a polymerization agent.

of $370 \mathrm{~nm}$ which can be assigned to the intrinsic band-gap absorption of $\mathrm{ZnO}$ due to the electron transitions from the valence band to the conduction band $\left(\mathrm{O}_{2 \mathrm{p}} \rightarrow \mathrm{Zn}_{3 \mathrm{~d}}\right) \cdot{ }^{11}$ In addition, this sharp peak shows that the particles are in nanosize, and the particle size distribution is narrow. It is clearly shown that the maximum peak in the absorbance spectrum does not correspond to the true optical band gap of the ZnO-NPs. A common way to obtain the band gap from absorbance

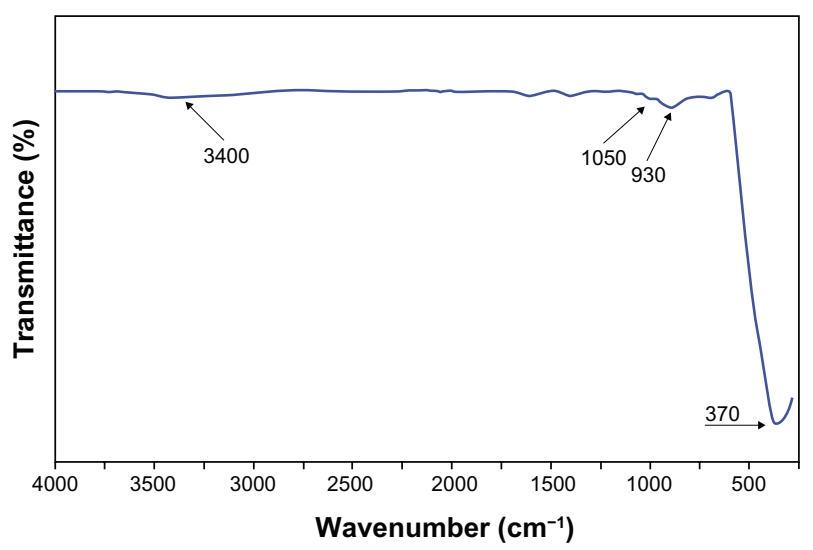

Figure 2 The Fourier transform infrared spectroscopy pattern of the zinc oxide nanoparticles prepared by the solvothermal method at $150^{\circ} \mathrm{C}$. spectra is to get the first derivative of the absorbance with respect to photon energy and find the maximum in the derivative spectrum at the lower energy sides. ${ }^{21}$ The derivative of the absorbance of the ZnO-NPs is shown in the inset of Figure 4, and it indicates a band gap of $3.3 \mathrm{eV}$ for the ZnO-NPs. The good absorption of the $\mathrm{ZnO}-\mathrm{NPs}$ in the $\mathrm{UV}$ region proves the applicability of this product in such medical application such as sunscreen protectors or as antiseptic ointments. ${ }^{\text {? }}$

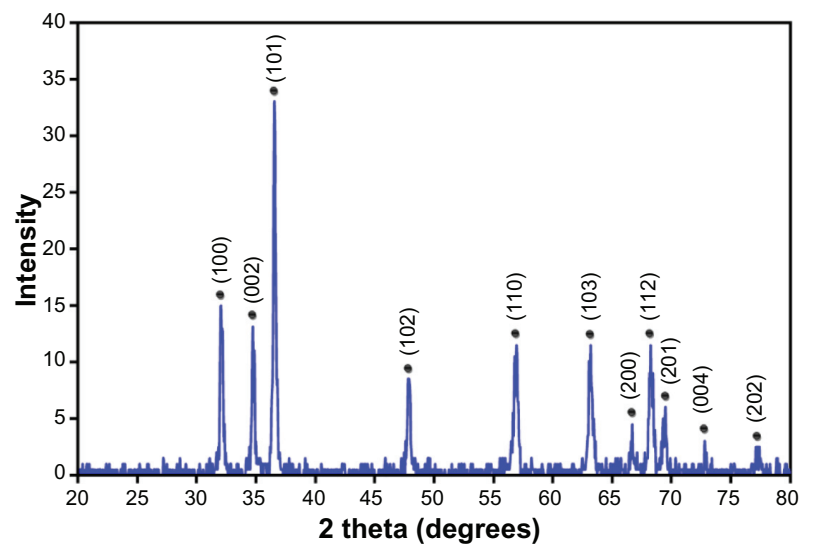

Figure 3 The $\mathrm{X}$-ray diffraction pattern of the zinc oxide nanoparticles prepared by the solvothermal method at $150^{\circ} \mathrm{C}$. 


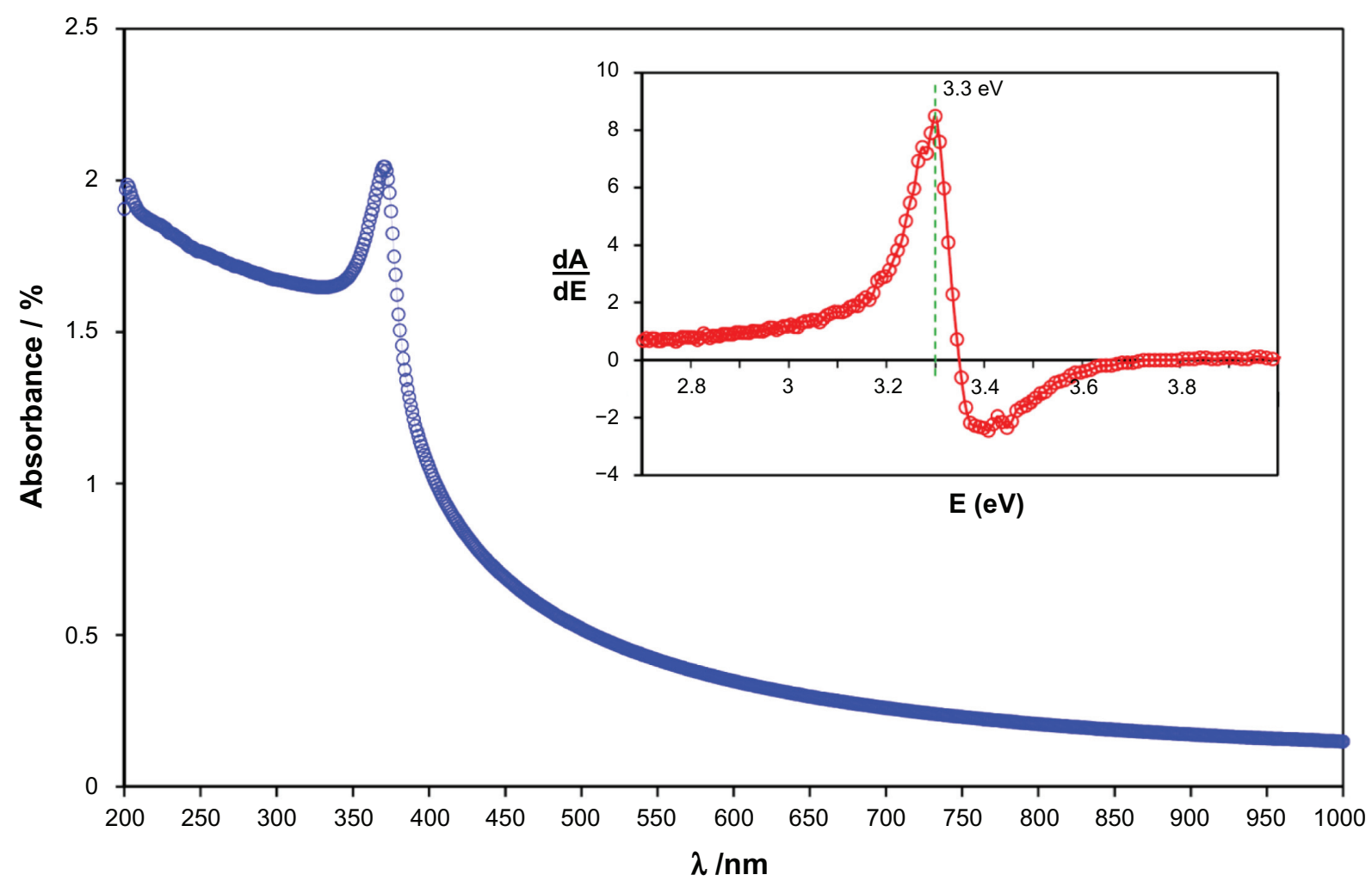

Figure 4 The UV-vis absorbance spectrum of zinc oxide nanoparticles from $200 \mathrm{~nm}$ to $1000 \mathrm{~nm}$. Inset shows the derivative of the absorbance spectrum.

\section{Morphology}

Figure 5 (A, B, and C) shows the TEM, SEM, and size distribution of the $\mathrm{ZnO}-\mathrm{NPs}$ prepared by the solvothermal method at $150^{\circ} \mathrm{C}$ for 18 hours. The TEM (Figure 5A) shows that the $\mathrm{ZnO}-\mathrm{NPs}$ have grown in a near-hexagonal shape, which demonstrates the good quality of the ZnO-NPs. Figure 5B shows the SEM micrograph of the ZnO-NPs at 150,000X magnification. The SEM figure indicates a homogeneous shape and size for ZnO-NPs. Also, it shows the ZnO-NPs are well dispersed in the powder form. The size histograms of the ZnO-NPs are shown in Figure 5c. The histograms indicate that the main particle sizes of the $\mathrm{ZnO}$-NPs made by the solvothermal method at temperature of $150^{\circ} \mathrm{C}$ for 6 hours is about $48 \pm 7 \mathrm{~nm}$.

The TEM, SEM, and size distribution results confirm that a narrow size distribution can be obtained for ZnO-NPs prepared by a solvothermal method using TEA as a polymerization agent, compared to some of the other results. ${ }^{10-12}$
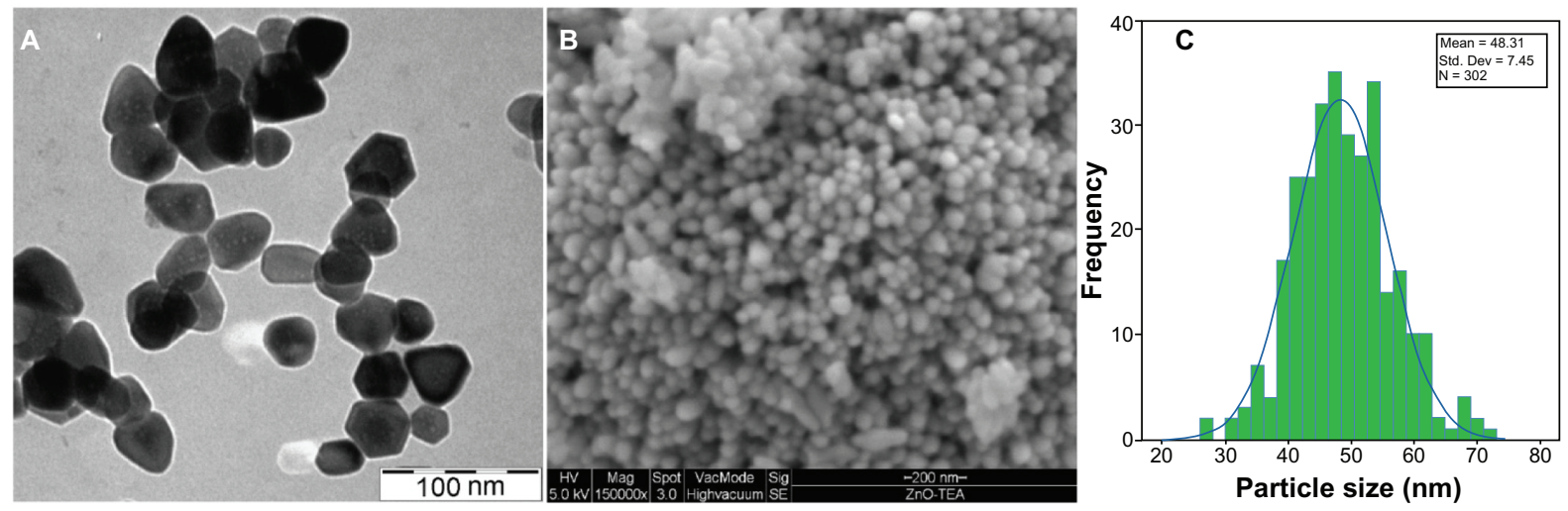

Figure 5 The transmission electron micrograph morphology image of zinc oxide nanoparticles (ZnO-NPs) (A), the scanning electron micrograph of the ZnO-NPs (B), and the particle size distribution of the $\mathrm{ZnO}-\mathrm{NPs}(\mathbf{C})$. 


\section{Conclusion}

The ZnO-NPs were made successfully by a solvothermal method at the low temperature of $150^{\circ} \mathrm{C}$ for 18 hours. TEA was used as a polymerization agent to control the growth of the ZnO-NPs because of its special structure that terminates the growth of the ZnO-NPs. The XRD results show that the $\mathrm{ZnO}-\mathrm{NPs}$ were formed in a hexagonal structure with crystalline size of $33 \pm 2 \mathrm{~nm}$. A sharp absorption peak $(370 \mathrm{~nm})$ was detected in the UV-vis region that corresponds to an optical band gap of the ZnO-NPs which was found to be $3.3 \mathrm{eV}$. TEM shows that the ZnO-NPs exhibit a nearhexagonal shape according to their crystalline structure. The $\mathrm{ZnO}$ powder was very homogeneous, as shown by SEM. The average particle size of $48 \pm 7 \mathrm{~nm}$ was obtained for $\mathrm{ZnO}-\mathrm{NPs}$ from the particle size distribution graph. The results confirm the quality of the $\mathrm{ZnO}-\mathrm{NPs}$, which make them suitable for medical applications.

\section{Acknowledgments}

This work was supported by the University of Malaya through grants no: UM.C/625/1/HIR/041.

\section{Disclosure}

The authors report no conflicts of interest.

\section{References}

1. Hanley C, Layne J, Punnoose A, et al. Preferential killing of cancer cells and activated human $\mathrm{T}$ cells using $\mathrm{ZnO}$ nanoparticles. Nanotechnology. 2008; 19:295103.

2. Lanone S, Boczkowski J. Biomedical applications and potential health risks of nanomaterials: molecular mechanisms. Curr Mol Med. 2006;6:651-663.

3. Groneberg DA, Giersig M, Welte T, Pison U. Nanoparticle-based diagnosis and therapy. Curr Drug Targets. 2006;7:643-648.

4. Padmavathy N, Vijayaraghavan R. Enhanced bioactivity of $\mathrm{ZnO}$ nanoparticles-an antimicrobial study. Sci Technol Adv Mat. 2008; 9:035004.

5. Qun L, Chen SL, Jiang WC. Durability of nano ZnO antibacterial cotton fabric to sweat. J Appl Polym Scie. 2007;103:412-416.
6. Akhavan O, Ghaderi E. Enhancement of antibacterial properties of Ag nanorods by electric field. Sci Technol Adv Mat. 2009;10:015003.

7. Harding F. Breast Cancer: Cause - Prevention - Cure. Aylesbury: Tekline Publishing; 2006:83.

8. Hughes G, McLean NR. Zinc oxide tape: a useful dressing for the recalcitrant finger-tip and soft-tissue injury. Arch Emerg Med. 1988;5(4):223-227.

9. Ying KL, Hsieh TE, Hsieh YF. Colloidal dispersion of nano-scale $\mathrm{ZnO}$ powders using amphibious and anionic polyelectrolytes. Ceram Inter. 2009;35:1165-1171.

10. Zak AK, Majid WH Abd, Darroudi M, Yousefi R. Synthesis and characterization of $\mathrm{ZnO}$ nanoparticles prepared in gelatin media. Mater Lett. 2011;65:70-73.

11. Zak AK, Abrishami ME, Majid WH Abd, Yousefi R, Hosseini SM. Effects of annealing temperature on some structural and optical properties of $\mathrm{ZnO}$ nanoparticles prepared by a modified sol-gel combustion method. Ceram Inter. 2011;37:393-398.

12. Wang Y, Zhang C, Bi S, Luo G. Preparation of ZnO nanoparticles using the direct precipitation method in a membrane dispersion microstructured reactor. Powder Technol. 2010;202:130-136.

13. $\mathrm{Lu} \mathrm{CH}$, Yeh $\mathrm{CH}$. Influence of hydrothermal conditions on the morphology and particle size of zinc oxide powder. Ceram Inter. 2000;26:351-357.

14. Sangkhaprom N, Supaphol P, Pavarajarn V. Fibrous zinc oxide prepared by combined electrospinning and solvothermal techniques. Ceram Inter 2010;36:357-360

15. Yousefi R, Muhamad MR, Zak AK. Investigation of indium oxide as a self-catalyst in $\mathrm{ZnO} / \mathrm{ZnInO}$ heterostructure nanowires growth. Thin Solid Films. 2010;518:5971-5977.

16. Cao Y, Liu B, Huang R, Xia Z, Ge S. Flash synthesis of flower-like $\mathrm{ZnO}$ nanostructures by microwave-induced combustion process. Mater Lett. 2011;65:160-163.

17. Mishra P, Yadav RS, Pandey AC. Growth mechanism and photoluminescence property of flower-like $\mathrm{ZnO}$ nanostructures synthesized by starch-assisted sonochemical method. Ultrason Sonochem. 2010; 17:560-565

18. Xu CH, Lui HF, Surya C. Synthetics of $\mathrm{ZnO}$ nanostructures by thermal oxidation in water vapor containing environments. Mater Lett. 2011;65:27-30.

19. Niederberger M, Pinna N. Metal Oxide Nanoparticles in Organic Solvents: Synthesis, Formation, Assembly and Application. London: Springer-Verlag; 2009.

20. Zak AK, Majid WH Abd, Abrishami ME, Yousefi R. Solid State Sci. 2011;13:251-256.

21. Becerril M, Silva-Lopez H, Zelaya-Angel O. Rev Me Fls. 2004;50(6): $588-593$.
International Journal of Nanomedicine

\section{Publish your work in this journal}

The International Journal of Nanomedicine is an international, peerreviewed journal focusing on the application of nanotechnology in diagnostics, therapeutics, and drug delivery systems throughou the biomedical field. This journal is indexed on PubMed Central,

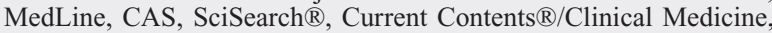

\section{Dovepress}

Journal Citation Reports/Science Edition, EMBase, Scopus and the Elsevier Bibliographic databases. The manuscript management system is completely online and includes a very quick and fair peer-review system, which is all easy to use. Visit http://www.dovepress.com/ testimonials.php to read real quotes from published authors. 